\title{
Spatial and temporal variation of chlorophyll $a$, primary productivity and chemical hydrography in the southern East China Sea
}

\author{
Gwo-Ching Gonga,*, Fuh-Kwo Shiah ${ }^{\mathrm{b}}$, Kon-Kee Liu ${ }^{\mathrm{b}}$, \\ Yun-Ho Wen ${ }^{\mathrm{a}}$, Ming-Hsin Liang ${ }^{\mathrm{a}}$
}

${ }^{a}$ Department of Oceanography, National Taiwan Ocean University, Keelung 202-24, Taiwan, Republic of China

${ }^{\mathrm{b}}$ Institute of Oceanography, National Taiwan University, Taipei, Taiwan, Republic of China

\begin{abstract}
Chemical hydrography, chlorophyll $a$ distribution and primary productivity in the southern East China Sea from the inner shelf to the offshore region were examined for their temporal and spatial variability based on observations along a cross-shelf transect during 1991-1995. In summer, all surface waters were depleted in nutrients and low in chlorophyll, resulting in widespread subsurface chlorophyll a maxima. In other seasons, shelf waters were usually nutrient-laden, but phytoplankton biomass was limited by light availability in the turbid inner shelf water and the short exposure time of the upwelled water in the outer shelf. The main nitrogen source in the inner shelf was from river runoff. Nitrate deficit, defined as the negative deviation from the conservative mixing line, was well correlated with phytoplankton biomass. In spite of the seasonal and spatial variability of chlorophyll $a$ distribution, the euphotic zone integrated value of chlorophyll $a$ was correlated well with that of primary production in shelf waters. This relationship was used to convert chlorophyll $a$ data from 28 cruises to primary production. The results showed that the lowest productivity on the shelf was in summer with little spatial variation. The elevated primary productivity in the inner shelves in spring was due to a mild spring bloom. On the other hand, the elevated primary productivity in the middle and outer shelves in autumn was due to the intensification of upwelling during the transition of the monsoon. The annual mean values of the euphotic zone integrated primary production in the shelf waters were quite uniform $\left(513-576 \mathrm{mgC} \mathrm{m}^{-2} \mathrm{~d}^{-1}\right)$ with an overall mean of $549 \pm 84 \mathrm{mgC} \mathrm{m}^{-2} \mathrm{~d}^{-1}$. The offshore Kuroshio Water showed a weak seasonal variation
\end{abstract}

\footnotetext{
* Corresponding author. Tel.: + 886-2-2462-9707; fax: + 886-2-2462-0330.
}

E-mail address: gcgong@mail.ntou.edu.tw (G.-C. Gong) 
(276-309 $\mathrm{mgC} \mathrm{m}^{-2} \mathrm{~d}^{-1}$ ) with an annual mean of $292 \pm 15 \mathrm{mgC} \mathrm{m}^{-2} \mathrm{~d}^{-1}$. (C) 2000 Elsevier Science Ltd. All rights reserved.

Keywords: Chlorophyll a; Primary productivity; Chemical hydrography; Nitrate deficit; Southern East China Sea

\section{Introduction}

The southern East China Sea (ECS) extending from the mainland coast of China to the offshore region northeast of Taiwan (Fig. 1) is a highly dynamic region because of the interaction of different water types (Gong et al., 1996): the China Coastal Water (CCW), the Taiwan Current Warm Water (TCWW), the Upwelled Water (UW) and the Kuroshio Water (KW). The four types of water usually occupy the inner-, middle-, outer-shelf and offshore region, respectively (Liu et al., 1992a; Gong et al., 1996). The hydrographic and nutrient conditions (denoted as chemical hydrography hereafter) have been demonstrated to regulate the phytoplankton biomass and primary productivity in the southern ECS in spring (Liu et al., 1995).

The chemical hydrography is in turn controlled by physical forcing. For example, Gong et al. (1997) reported that retreat of the Kuroshio intrusion from the shelf northeast of Taiwan restored the upwelling center, which resulted in a doubling of the

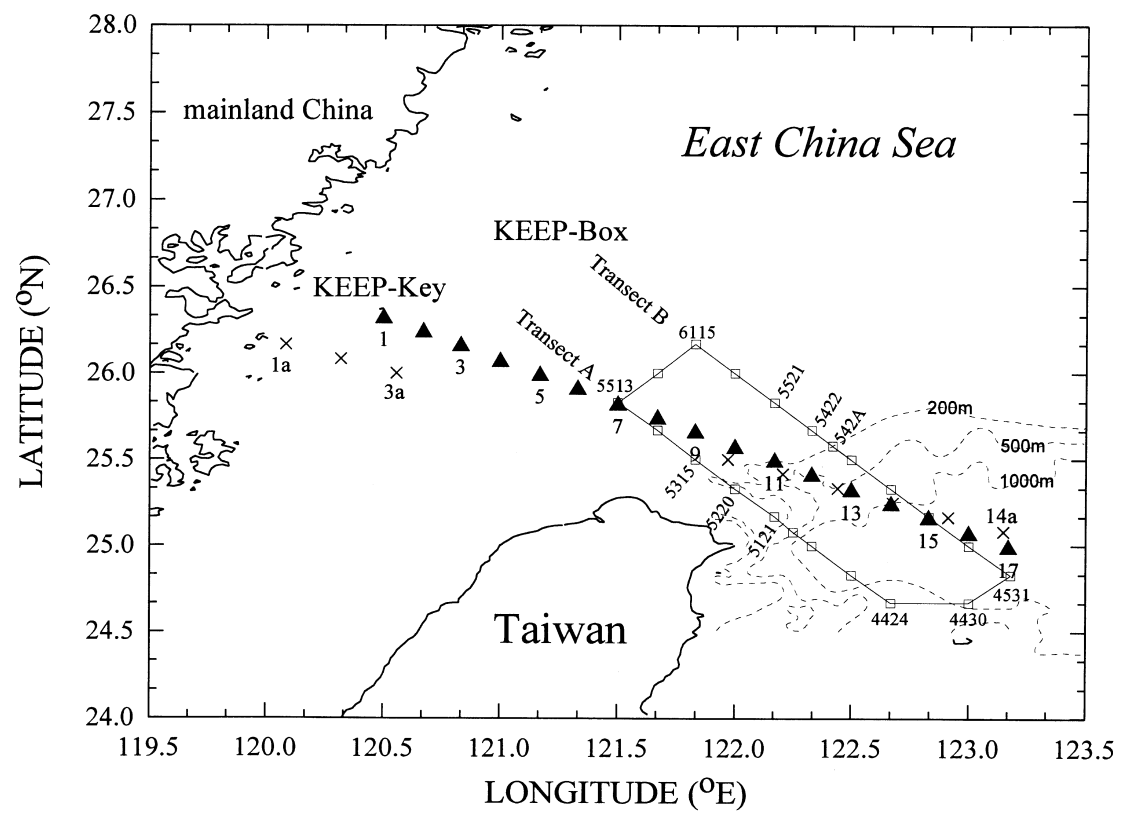

Fig. 1. Station locations for the KEEP-Box $(\square)$, KEEP-Key $(\boldsymbol{\Delta})$ cruises and Cruise $414(\times)$. 
phytoplankton biomass around the cyclonic eddy within two weeks. This illustrates that temporal variation of primary productivity cannot be properly interpreted, if only data on local primary productivity are examined without understanding of regional processes. On the other hand, the overall phytoplankton biomass might not have increased as much, because the event seemed to have involved only redistribution of nutrients instead of net increase of nutrient supply. A synoptic regional survey would be essential to tackle this kind of problems. Fortunately, the large-scale synoptic near surface chlorophyll $a(\mathrm{Chl} a)$ data are now available from the satellite ocean color sensors, such as the recently launched SeaWiFS (Sea-viewing Wide Field-of-view Sensor). Increasing availability of the satellite-derived Chl $a$ data will undoubtedly provide us with more accurate assessment of global primary productivity. However, regionally specific algorithm is needed for the conversion of Chl $a$ data into primary productivity. Bio-optical models, such as the semi-analytical photosynthesis-irradiance $\left(\mathrm{P}^{\mathrm{B}}-\mathrm{E}\right)$ model or the analytical absorption model (Morel, 1991), are widely used, but photosynthetic parameters may not be easy to come by. Alternatively, the euphotic zone integrated primary production (IP) has been successfully estimated simply from the regional empirical relationship between Chl $a$ and primary production (e.g., Ryther and Yentsch, 1957; Lorenzen, 1970; Smith and Baker, 1978; Hayward and Venrick, 1982; Eppley et al., 1985; Yoder et al., 1993; Mantyla et al., 1995).

In the present paper, spatial and temporal variations of chemical hydrographic conditions and Chl $a$ distributions in the southern ECS observed along a cross-shelf transect on 13 cruises between 1990 and 1995 are systematically examined. The control of phytoplankton biomass by nutrient, light and other factors is addressed. Primary productivity data are available on some of the more recent cruises. In order to better assess primary productivity in the study region, we established relationships between Chl $a$ and primary productivity, which in turn enabled us to estimate the missing primary productivity data. Thus, we obtained a temporally and spatially comprehensive data set of primary productivity for the southern ECS covering four seasons and four regions of different water characteristics.

\section{Materials and methods}

\subsection{Study area and data collections}

The data collected from October 1991 to September 1995 along a long transect, named as KEEP-Key transect, were used to study the seasonal variability of chemical hydrography, Chl $a$ and primary productivity in different water masses of the southern ECS. The KEEP-Key transect (Fig. 1) extends from the inner shelf near the mainland China coast to the offshore region where the Kuroshio flows. A total of 13 cruises were conducted. Detailed information about the dates of the cruises, sampling stations and variables measured are listed in Table 1. Extracted Chl $a$ samples were first collected in May 1993. Before that, Chl $a$ concentrations were estimated from calibrated fluorescence data (Gong et al., 1993, 1995b). Primary productivity (PP) 
measurements were conducted on Cruises 386, 405C and 414 onboard R/V Ocean Researcher I, and on Cruises 034, 111, 131 and 149 onboard R/V Ocean Researcher II. The calibrated fluorescence data collected from the KEEP-Box cruises during the period of August 1989 to July 1990 and the KEEP-IOP (Intensive Observation Period) cruises during the period of September 1992 to May 1993 (Fig. 1; Table 1) were used to calculate primary production with the empirical relationship between Chl $a$ and PP established in this study.

\subsection{Sampling Instruments and analytical methods}

Profiles of temperature $(T)$ and salinity $(S)$ were measured by a SeaBird CTD (SBE9/11plus, SeaBird Inc., USA). Light transmission (LT), fluorescence (F) and total downwelling scalar irradiance (PAR) profiles were measured, respectively, with a transmissometer (25 cm light path at $660 \mathrm{~nm}$, Sea Tech Inc.), a fluorometer (Sea Tech Inc.) and a quantum scalar irradiance meter ( $4 \pi$ collector; Biospheric Inc., USA) attached to the CTD. Seawater samples were collected using the Rosette sampler (General Oceanic Inc., USA) with Teflon-coated Go-Flo bottles (General Oceanic Inc., USA) mounted on the CTD assembly. The depth of the euphotic zone was defined as the depth of $1 \%$ surface light penetration. The CTD salinity data were double-checked with manually determined salinity by the Autosal (8400B; Guildline Inc., Canada) after each cruise.

Table 1

Cruise information

\begin{tabular}{|c|c|c|c|c|c|}
\hline Cruise no. & $\mathrm{R} / \mathrm{V}$ & $\begin{array}{l}\text { Date } \\
\text { (mm/dd, yyyy) }\end{array}$ & Season & Stations visited & $\begin{array}{l}\text { Variables } \\
\text { measured }\end{array}$ \\
\hline 297 & OR1 & $10 / 05-07,1991$ & Autumn & $1-10$ & $T, S, N, F$ \\
\hline 304 & OR1 & 12/09-11, 1991 & Winter & $10-15$ & $T, S, F$ \\
\hline 307 & OR1 & 01/05-08, 1992 & Winter & $8-12,14,16,17$ & $T, S, N, O, F$ \\
\hline 314 & OR1 & $04 / 16-22,1992$ & Spring & $1-12,14,16,17$ & $T, S, N, O$ \\
\hline 323 & OR1 & $07 / 10-15,1992$ & Summer & $1-17$ & $T, S, N, O, F$ \\
\hline 373 & OR1 & 11/01-07, 1993 & Autumn & $1,3,5,7,8,10-17$ & $T, S, N, O, F, C$ \\
\hline 386 & OR1 & 05/04-10, 1994 & Spring & $1^{\mathrm{a}}, 2-7,8^{\mathrm{a}}, 10,11^{\mathrm{a}}, 12-16,17$ & $T, S, N, O, F, C, P$ \\
\hline $405 \mathrm{C}$ & OR1 & 11/06-12, 1994 & Autumn & $1^{\mathrm{a}}, 2,5^{\mathrm{a}}, 6-10,11^{\mathrm{a}}, 14,17^{\mathrm{a}}$ & $T, S, N, O, F, C, P$ \\
\hline 414 & OR1 & $03 / 22-28,1995$ & Spring & $1 \mathrm{a}^{\mathrm{a}}, 3 \mathrm{a}^{\mathrm{a}}, 9 \mathrm{a}^{\mathrm{a}}, 10 \mathrm{a}, 11 \mathrm{a}, 14 \mathrm{a}^{\mathrm{a}}$ & $T, S, N, O, F, C, P$ \\
\hline 034 & OR2 & $09 / 13-15,1994$ & Autumn & $6-8,9^{\mathrm{a}}, 10^{\mathrm{a}}, 11-13$ & $T, S, N, O, F, C, P$ \\
\hline 111 & OR2 & 05/01-04, 1995 & Spring & $11^{\mathrm{a}}, 12-16,17^{\mathrm{a}}$ & $T, S, N, O, F, C, P$ \\
\hline 131 & OR2 & $07 / 01-04,1995$ & Summer & $8-10,11^{\mathrm{a}}, 13,15,17^{\mathrm{a}}$ & $T, S, N, O, F, C, P$ \\
\hline 149 & OR2 & 09/01-04, 1995 & Autumn & $8,9,11^{\mathrm{a}}, 13,15,17^{\mathrm{a}}$ & $T, S, N, O, F, C, P$ \\
\hline KEEP-Box & OR1 & $08,1990-07,1991$ & Monthly & See Fig. 1 & $T, S, N, O, F$ \\
\hline KEEP-IOP & OR1 & $\begin{array}{l}09-10,1992 \text { and } \\
04-05,1993\end{array}$ & $\begin{array}{l}\text { Autumn } \\
\text { and Spring }\end{array}$ & See Fig. 9 & $T, S, N, O, F, C$ \\
\hline
\end{tabular}

${ }^{\text {a }}$ Primary productivity experiments were performed.

$T$ : temperature, $S$ : salinity, $N$ : nutrients, $O$ : dissolved oxygen, $F$ : fluorescence, $C$ : chlorophyll, $P$ : primary productivity 
Water samples for nutrient measurements were placed in a $100 \mathrm{ml}$ polypropylene bottles and frozen immediately with liquid nitrogen. Nitrate was analyzed with a self-designed flow injection analyzer and was reduced to nitrite with a cadmium wire which was activated with a copper sulfate solution (Gong, 1992). The precision for the nitrate analysis was $0.3 \mu \mathrm{M}$ for concentrations of $10 \mu \mathrm{M}$ or higher. Dissolved oxygen was measured by spectrophotometry (Pai et al., 1993). Water samples for Chl $a$ analysis were immediately filtered through a $\mathrm{GF} / \mathrm{F}$ filter paper (Whatman, $47 \mathrm{~mm}$ ) and stored at $-20^{\circ} \mathrm{C}$. Chl $a$ retained on $\mathrm{GF} / \mathrm{F}$ filters were determined fluorometrically (Strickland and Parsons, 1972; Gong et al., 1993, 1995b). The GF/F filters were ground in $10 \mathrm{ml} 90 \%$ acetone followed by extraction in a $4{ }^{\circ} \mathrm{C}$ shaking incubator for at least $2 \mathrm{~h}$. After centrifugation $(1000 \times g ; 5 \mathrm{~min})$, the Chl $a$ concentration in the supernatant was measured with a fluorometer (Turner; 10-AU-005).

Primary productivity (PP) was measured by the ${ }^{14} \mathrm{C}$ assimilation method (Parsons et al., 1984; Shiah et al., 1995). Acid-cleaned polycarbonate bottles ( $250 \mathrm{ml}$, Nalgene) were filled with seawater prescreened through $200 \mu \mathrm{m}$ mesh, and then inoculated with $10 \mu \mathrm{Ci} \mathrm{NaH}{ }^{14} \mathrm{CO}_{3}$. Samples were incubated in situ from dawn to dusk on the three cruises in 1995. On Cruises 405C and 034, samples were incubated on deck using sunlight as the light source, and incubators were cooled with running surface seawater. Following retrieval, the samples were filtered through $\mathrm{GF} / \mathrm{F}$ filters (Whatman, $25 \mathrm{~mm})$ under low vacuum $(<100 \mathrm{mmHg})$. The filters then were placed in scintillation vials and stored in dark. Upon returning to the laboratory, $0.5 \mathrm{ml}$ of $2 \mathrm{~N} \mathrm{HCl}$ was added and the vials were left open overnight in a hood at room temperature. Next, $10 \mathrm{ml}$ of scintillation cocktail (Ultima Gold LLT) was added, and total activity on filters was counted in a liquid scintillation counter (Packard 2700TR). Euphotic zone integrated $\mathrm{Chl} a$ (IB) and primary production (IP) was calculated by trapezoid rule.

\section{Results}

Hydrographic data and profiles of Chl $a$ and PP obtained during 1990-1995 (Table 1) are presented in four groups, representing the inner, middle and outer shelves and the offshore region. The corresponding localities are represented by Stations 1-3, 5-7, 9-11 and 15-17 along the cross-shelf KEEP-Key transect (Fig. 1). The data collected during periods of March-May, June-August, September-November and December-February are designated as spring, summer, autumn and winter, respectively. In general, the summer condition is distinctively different from those of other seasons. Therefore, summer and non-summer conditions are presented separately in two sets of plots for each region.

\subsection{The inner shelf}

The scatter diagram of $T-S$ and the vertical distributions of $\mathrm{NO}_{3}, \mathrm{Chl} a$, and PP concentrations obtained in September-May are shown in the top panels of Fig. 2, and those in June-August are in the bottom panels. All inner shelf waters showed wide ranges of salinity $(<29$ to $34 \mathrm{psu})$ with the lowest salinities observed from November 

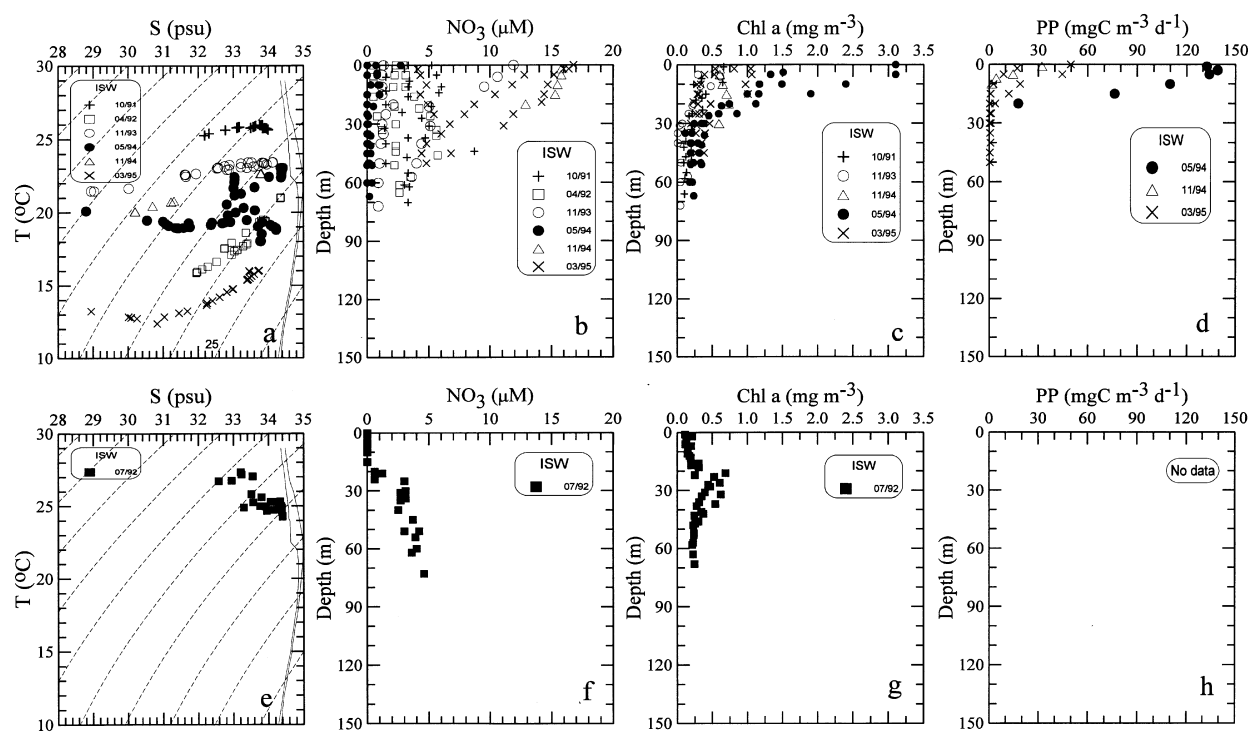

Fig. 2. The $T-S$ diagram, and the vertical profiles of nitrate $\left(\mathrm{NO}_{3}\right), \mathrm{Chl} a$ and primary productivity $(\mathrm{PP})$ in the inner shelf waters (ISW) in various seasons. The top panels are for non-summer seasons and the bottom ones are for summer.

to May. Since occurrences of very low salinity waters were during the dry period of low riverine discharge, apparently, the salinity change in this region was not directly controlled by changes in river runoff as suggested by Chen (1996), but by coastal circulation. The riverine discharges, most notably from Changiiang, starts to flow southward along the coast after the onset of the northeast monsoon in mid September (Beardsley et al., 1985; Chao, 1991). It is usually in November that the very low salinity water reaches the southern ECS according to our records (Liu et al., 1993).

By contrast, the water temperatures were usually in a narrow range on a single cruise but changed from cruise to cruise, spanning from $12^{\circ} \mathrm{C}$ in March to $27^{\circ} \mathrm{C}$ in July. Strong salt gradient existed both vertically and horizontally with fresher water on top and usually hugging to the coast. Although no data were obtained for winter due to the rough sea conditions, the hydrographic conditions in winter should be similar to those found in spring and autumn in light of previous observations (Wang and Chern, 1988).

Vertical distributions of $\mathrm{NO}_{3}$ in the inner shelf are shown in Fig. 2(b). One of the most striking features is the seemingly inverse profile with maximum concentration at the surface and decreasing with depth. The highest concentration in the surface water reached as high as $17 \mu \mathrm{M}$. Such profiles all occurred in November and March, when very low salinity water was prevalent. Apparently, the low salinity water received ample supply of nitrate from riverine discharges (Zhang, 1996). However, very low salinity water was still observed in May, but nitrate concentrations dropped to nearly zero throughout the water column. 
The vertical distributions of Chl $a$ concentrations were generally high in the surface layer and decreased rapidly with depth (Fig. 2(c)). The values of Chl $a$ concentrations in surface water varied in a wide range from about 0.5 to above $3 \mathrm{mg} \mathrm{m}^{-3}$. The highest values of Chl $a$ concentration were observed in late spring (May), suggesting a spring bloom. The values of IB in the euphotic zone were between 5 and $46 \mathrm{mg} \mathrm{m}^{-2}$.

Only three profiles of PP data were obtained in the inner shelf (Fig. 2(d)). They are similar to those of $\mathrm{Chl} a$ with higher values in the surface and decreasing rapidly with depth. The values of PP in surface waters ranged from 20 to $140 \mathrm{mgC} \mathrm{m}^{-3} \mathrm{~d}^{-1}$. The highest PP corresponded to the highest Chl $a$ concentrations observed in May 1994. PP essentially vanished below the top $25 \mathrm{~m}$. The values of IP ranged from 76 to $1900 \mathrm{mgC} \mathrm{m}^{-2} \mathrm{~d}^{-1}$.

In summer, the observed salinity ranges ( 32.5 to $34.4 \mathrm{psu}$ ) were smaller than those of other seasons (Fig. 2(e)). $\mathrm{NO}_{3}$ concentrations were almost non-detectable in the top $20 \mathrm{~m}$ and increased with depth to about $5 \mu \mathrm{M}$ at the bottom (Fig. 2(f)). The vertical distributions of Chl $a$ showed an eminent subsurface maximum centered around $30 \mathrm{~m}$ with concentration up to about $0.7 \mathrm{mg} \mathrm{m}^{-3}$ (Fig. 2(g)). The values of IB were about $17 \mathrm{mg} \mathrm{m}^{-2}$. No PP data were available for summer.

The percentage of light transmission in the surface layer was high in summer $(>70 \%)$ and low in late autumn $(<50 \%)$. Typical values observed at Sta 1 on three different cruises are listed in Table 2 . Vertically, a minimum usually existed in the bottom layer $(<25 \%)$, apparently due to sediment resuspension (Hung et al., this volume). The generally lower light transmission observed in late autumn implied a higher intensity of sediment resuspension under the action of persistent northeast monsoon, which even reduced the light penetration in the surface water. The euphotic zone depth in late autumn was only $10 \mathrm{~m}$ on average.

\subsection{The middle shelf}

Hydrographic conditions and Chl $a$ distributions in the middle shelf resembled those in the inner shelf in summer, but not in other seasons (Fig. 3). The salinity values

Table 2

The variation of daily averaged irradiance, mean light transmission, nitrate concentration, seawater temperature depth-integrated $\mathrm{Chl} a$ (IB) and primary production(IP) in the euphotic zone at Station 1 observed on three cruises

\begin{tabular}{llll}
\hline $\begin{array}{l}\text { Season } \\
\text { Date } \\
(\text { Cruise })\end{array}$ & $\begin{array}{l}\text { Early spring } \\
\text { March 1995 } \\
\text { (Cruise 414) }\end{array}$ & $\begin{array}{l}\text { Late spring } \\
\text { May 1994 } \\
\text { (Cruise 386) }\end{array}$ & $\begin{array}{l}\text { Late autumn } \\
\text { November 1994 } \\
\text { (Cruse 405C) }\end{array}$ \\
\hline $\mathrm{IB}\left(\mathrm{mg} \mathrm{m}^{-2}\right)$ & 4.8 & 46.0 & 5.6 \\
$\mathrm{IP}\left(\mathrm{mgC} \mathrm{m}^{-2} \mathrm{~d}^{-1}\right)$ & 76 & 1900 & 120 \\
Mean NO$(\mu \mathrm{M})$ & 15.4 & 0.8 & 15.7 \\
Solar irradiance $\left(\mu \mathrm{E} \mathrm{m}^{-2} \mathrm{~s}^{-1}\right)$ & 450 & 1500 & 1400 \\
Light transmission $(\%)$ & $55\left(2.05 \mathrm{~m}^{-1}\right)^{\mathrm{a}}$ & $75\left(0.79 \mathrm{~m}^{-1}\right)$ & $48\left(2.57 \mathrm{~m}^{-1}\right)$ \\
Temperature $\left({ }^{\circ} \mathrm{C}\right)$ & 15 & 17 & 19 \\
\hline
\end{tabular}

\footnotetext{
${ }^{\mathrm{a}}$ Beam attenuation coefficient of suspended particles.
} 

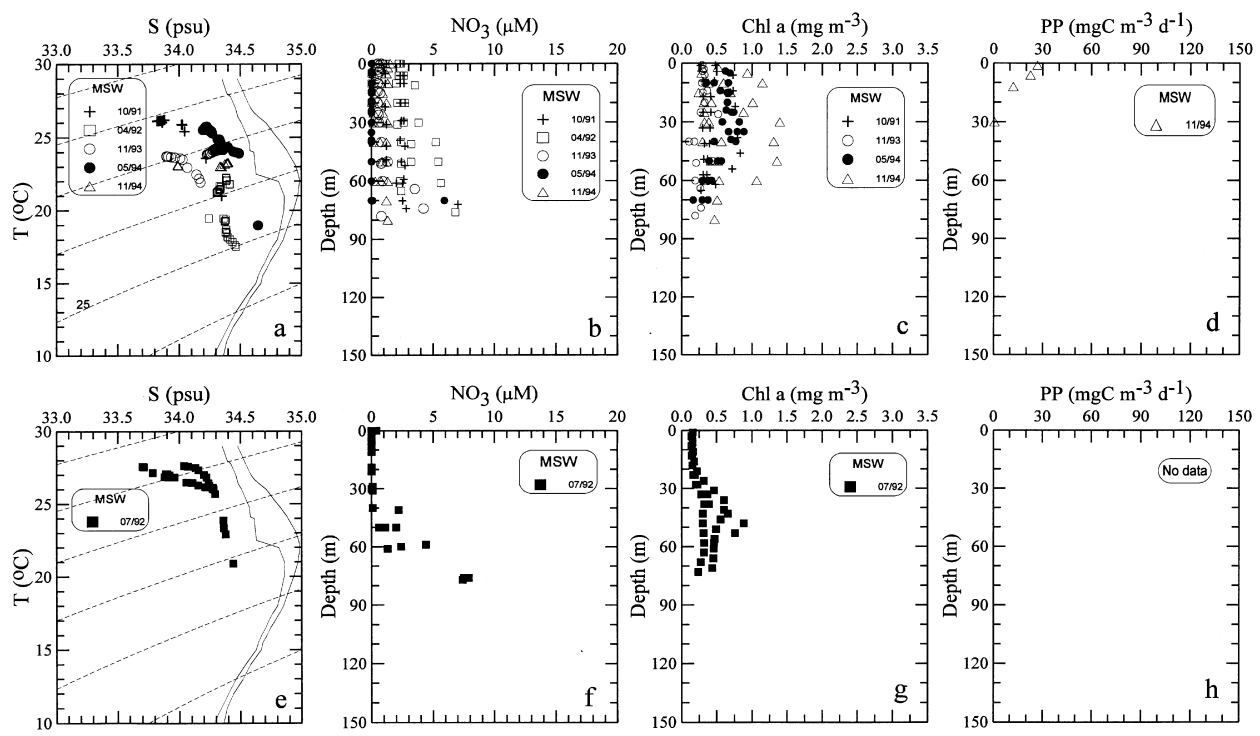

Fig. 3. Same as Fig. 2 except for the middle shelf waters (MSW).

were considerably higher, ranging from 33.7 to 34.4 psu (Fig. 3(a)). Highly enriched nitrate concentrations in the surface layer were not observed. Instead, nitrate concentrations fell to $3 \mu \mathrm{M}$ in the surface water and $7 \mu \mathrm{M}$ in the bottom water (Fig. 3(b)). Total depletion of nitrate in the top $40 \mathrm{~m}$ occurred in late spring and summer (Figs. $3(\mathrm{~b})$ and (f)).

The vertical distribution of Chl $a$ showed a distinctive subsurface maximum in summer (Fig. 3(g)) like that in the inner shelf (Fig. 2(g)). In other seasons, Chl $a$ concentrations were fairly uniform in the top $40 \mathrm{~m}$ at any given station and decreased with depth beneath (Fig. 3(c)). The average Chl $a$ concentrations in the upper $40 \mathrm{~m}$ ranged from 0.3 to $1.2 \mathrm{mg} \mathrm{m}^{-3}$. The depth of the euphotic zone was about $50 \mathrm{~m}$ on the average. The values of IB ranged from 11 to $56 \mathrm{mg} \mathrm{m}^{-2}$. Only one PP data was obtained in the November 1994 cruise (Fig. 3(d)). The value of IP was $340 \mathrm{mgC} \mathrm{m}^{-2} \mathrm{~d}^{-1}$.

Contrary to the inner shelf where the highest values of salinity were observed in summer, the salinity in the middle shelf showed its lowest values ( $33.7 \mathrm{psu})$ in summer (Fig. 3(e)). The low salinity and low nitrate water in the middle shelf probably originated from the South China Sea, where waters with similar characteristics have been observed (Gong et al., 1992). The northward flow through the Taiwan Strait from the South China Sea is supposedly the strongest in summer feeding the TCWW in the ECS shelf (Chuang, 1986; Shaw, 1989). Consequently, this northward flow causes wide-spread two-layer structure in the water column of the southern ECS with relatively fresh, warm, nutrient-depleted water in the surface layer and colder, more saline, nutrient-laden water in the bottom layer. Nutrients in the bottom water apparently originated from the Kuroshio upwelling (Gong et al., 1995a). 
The vertical distribution of Chl $a$ in summer was similar to that in the inner shelf, but the depth of the subsurface Chl $a$ maximum (ca. $50 \mathrm{~m}$ ) was deeper (cf. Figs. 2(g) and 3(g)) obviously due to a deeper nitracline (cf. Figs. 2(f) and 3(f)). The depth of euphotic zone was about $55 \mathrm{~m}$ on the average. The values of IB were about $19 \mathrm{mg} \mathrm{m}^{-2}$. No PP data in summer were available.

\subsection{The outer shelf}

Throughout the year, $T-S$ curves (Figs. 4(a) and (e)) of the outer shelf water converge to the region around $15^{\circ} \mathrm{C}$ and 34.6 psu with $\sigma_{\theta}=25.6$, representing the upwelling source water (Wong et al., 1991; Liu et al., 1992b; Gong et al., 1995a). Such a $T-S$ feature indicates the persistence of the upwelling process (Liu et al., 1992a). In the upper water column, the $T-S$ properties fall into two trends (Fig. 4(a)): one resembling the Kuroshio Water and the other more influenced by the shelf water. The two separate trends indicated the existence of different types of end members in the surface layer. One type was warmer and more saline, obviously originating from the Kuroshio surface water. The other had lower temperature and salinity, most likely containing some CCW which made excursion eastward from the middle shelf (Gong et al., 1995a).

The vertical distributions of $\mathrm{NO}_{3}$ usually showed enrichment throughout the water column with the maximum value consistently approaching $10 \mu \mathrm{M}$ or higher near the bottom (Fig. 4(b)). However, the surface concentration varied greatly, ranging from almost undetectable to about $10 \mu \mathrm{M}$. The highest surface $\mathrm{NO}_{3}$ concentration was observed at Station 11 on the November 1993 cruise. The lowest surface
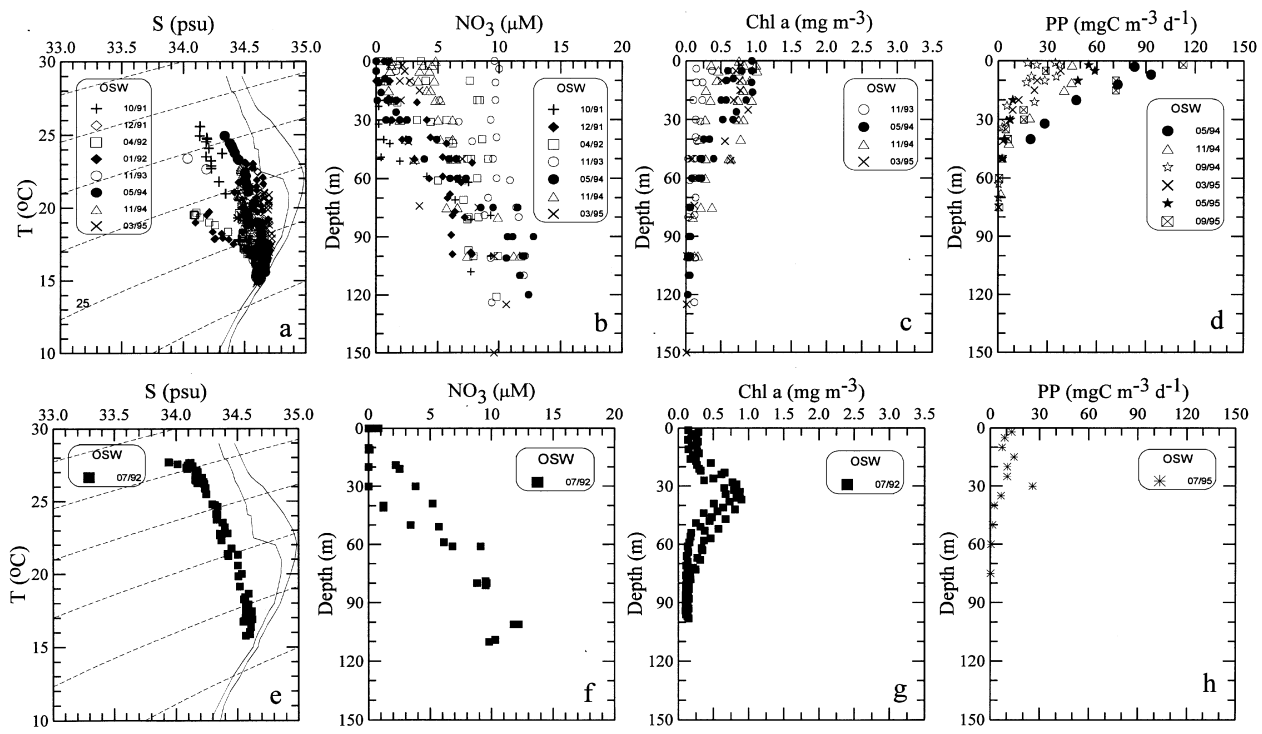

Fig. 4. Same as Fig. 2 except for the outer shelf waters (OSW). 
concentration was observed on the December 1991 cruise (Fig. 4(b)), while the bottom nitrate concentration was also the lowest $(8 \mu \mathrm{M})$, suggesting that the strength of the upwelling could be lower during a strong intrusion of the Kuroshio surface layer. This is consistent with direct observations of the upwelling fluxes (Liu et al., this volume).

In seasons other than summer, the vertical distributions of Chl $a$ in the upper $30 \mathrm{~m}$ showed little variation with depth but changed from cruise to cruise ranging between 0.1 and $1.0 \mathrm{mg} \mathrm{m}^{-3}$ (Fig. 4(c)). Below the top $30 \mathrm{~m}, \mathrm{Chl} a$ decreased with depth. The depth of the euphotic zone ranged from 50 to $70 \mathrm{~m}$ with a mean about $60 \mathrm{~m}$. The values of IB ranged from 12 to $39 \mathrm{mg} \mathrm{m}^{-2}$. The measured values of PP were high in the surface and decreased rapidly with depth (Fig. 4(d)). The values of PP in the surface waters were also highly variable, ranging from 20 to $110 \mathrm{mgC} \mathrm{m}^{-3} \mathrm{~d}^{-1}$. The values of IP ranged from 430 to $1520 \mathrm{mgC} \mathrm{m}^{-2} \mathrm{~d}^{-1}$.

In summer, a rather strong subsurface maximum of Chl $a$ was repeatedly observed (Fig. 4(g)). The maximum was centered at depth between 30 and $40 \mathrm{~m}$ with concentrations between 0.6 and $0.8 \mathrm{mg} \mathrm{m}^{-3}$. The depths of the euphotic zone were about $65 \mathrm{~m}$ on the average. The values of IB were around $22 \mathrm{mg} \mathrm{m}^{-2}$. The vertical distribution of PP showed little variation with depth in the upper $25 \mathrm{~m}$ (Fig. 4(h)). The value of IP was $460 \mathrm{mgC} \mathrm{m}^{-2} \mathrm{~d}^{-1}$.

\subsection{The offshore water}

The offshore water was usually dominated by the Kuroshio Water as indicated by the $T-S$ diagram (Fig. 5(a)), but, in summer, low salinity was observed in the surface
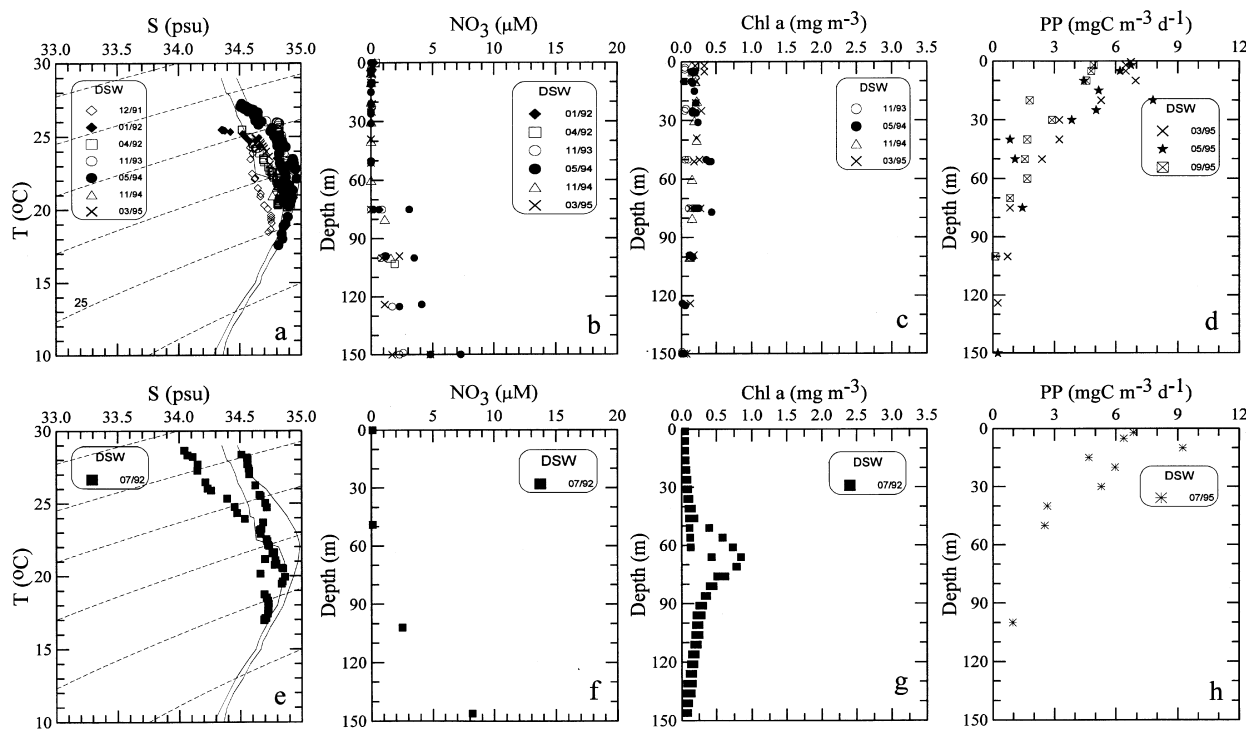

Fig. 5. Same as Fig. 2 except for the offshore deep sea waters (DSW). Solid curves represent the mean $T-S$ characteristics of the Kuroshio (Gong et al., 1995a). 
layer (Fig. 5(e)). The less saline water was probably an outflow of the shelf water (Chern et al., 1990; Liu et al., this volume). The surface temperatures were always higher than $25^{\circ} \mathrm{C}$ for all seasons of the year. The vertical distributions of $\mathrm{NO}_{3}$ showed that the upper $60 \mathrm{~m}$ were always impoverished and concentration increased gradually with depth thereunder (Figs. 5(b) and (f)).

The vertical distributions of Chl $a$ showed a strong subsurface maximum centered at depth between 60 and $70 \mathrm{~m}$ with concentration up to $0.8 \mathrm{mg} \mathrm{m}^{-3}$ in summer (Fig. 5(g)). In other seasons, Chl $a$ profiles showed a broadened subsurface maximum with concentration always lower than $0.5 \mathrm{mg} \mathrm{m}^{-3}$ (Fig. 5(c)). The depths of euphotic zone were about $100 \mathrm{~m}$ on the average. The values of IB ranged between 17 and $22 \mathrm{mg} \mathrm{m}^{-2}$. The vertical distributions of PP show highest value at surface and a gradual decrease with depth and vanishing to null for depth below $100 \mathrm{~m}$ (Fig. 5(d)), but a local maximum existed at $10 \mathrm{~m}$ below the surface in summer (Fig. 5(h)). The values of IP ranged between 180 and $335 \mathrm{mgC} \mathrm{m}^{-2} \mathrm{~d}^{-1}$.

\section{Discussion}

We attempt to find the correlation between $\mathrm{Chl} a$ abundance and primary productivity. However, the relationships are dependent on the vertical distribution of Chl $a$, which in turn was controlled by nutrient supply and other hydrographic conditions.

\subsection{Nitrogen supply, light penetration and Chl a distribution}

The vertical distributions of Chl $a$ in the southern ECS showed an interesting dichotomy. In summer, all regions showed the same pattern of a distinctive subsurface maximum of $\mathrm{Chl} a$ with a similar concentrations $\left(0.5-0.8 \mathrm{mg} \mathrm{m}^{-3}\right)$, which were centered at the nitracline (Figs. 2(g)-5(g)). In other seasons, Chl $a$ distribution varied markedly from region to region but most profiles showed relatively high concentration at the surface (Figs. 2(c)-5(c)). Different controlling factors must have governed the two distinct types of $\mathrm{Chl} a$ distribution.

Nutrient limiting conditions prevailed in strongly stratified water columns, which prevented upward supply of nutrients from the subsurface layer. The best developed subsurface Chl $a$ maximum was found in the offshore water in summer. The surface water reached temperatures above $28^{\circ} \mathrm{C}$ with $\sigma_{\Theta}$ less than 21.5 (Figs. 2(e)-5(e)). Besides high sea surface temperature, the stratification was further enhanced by a reduced salinity at the surface, which could have resulted from local precipitation and summer runoff or come from the South China Sea via the northward flow in the Taiwan Strait. This warm, less saline and nutrient-depleted water, under the forcing of the prevailing southwest monsoon (Gong et al., 1992), widely spread on the shelf with the maximum thickness in the middle shelf (Fig. 3(f)). The Chl $a$ build-up corresponded exactly to the gradual increase of nitrate below the surface mixed layer (Figs. 5(f) and (g)). Besides nutrient limitation, other causes may also contribute to the formation of secondary chlorophyll maximum (e.g. Longhurst and Harrison, 1989), but they are beyond the scope of this discussion. 
Aside from summer, inner shelf waters almost never lacked nitrate, but the Chl $a$ concentrations in the surface water varied in a wide range: $0.4-3.2 \mathrm{mg} \mathrm{m}^{-3}$ (Fig. 2). Three observations at Station 1 in different seasons are compared in Table 2. The low Chl $a$ and PP observed on Cruise 414 (March 1995) may be attributed to the low solar irradiance and high turbidity in water column as shown by the low light transmission (Table 2). The rather low temperature might have also limited the phytoplankton growth. Similarly low Chl $a$ and PP were observed on Cruise 405C in late autumn. Although solar irradiance was normal on that cruise, the light transmission in the euphotic zone was the lowest (Table 2). A high loading of total suspended matter in the water column was observed and attributed to sediment resuspension induced by strong wind during northeast monsoon (Hung et al., this volume). Limited light penetration was probably responsible for the low phytoplankton biomass. Of course, one might suspect that availability of micronutrients, such as iron, could be the limiting factors for the high-nitrate low-chlorophyll conditions (e.g., Martin, 1991). This is unlikely because the coastal sediments are rich in reactive iron $\left(>10 \mathrm{mg} \mathrm{g}^{-1}\right.$; Huang and Lin, 1995) and the estimated flux of total iron from the atmosphere to the ECS is also quite high (more than $1000 \mathrm{mg} \mathrm{m}^{-2} \mathrm{yr}^{-1}$; Duce and Tindale, 1991).

The nutrient loading in the CCW seemed to follow mixing trend between nutrientladen river runoff and nutrient-depleted saline offshore water (Fig. 6). The negative correlation between nitrate and salinity appeared to result from conservative mixing, but the mixing trends changed from cruise to cruise and significant deviations from

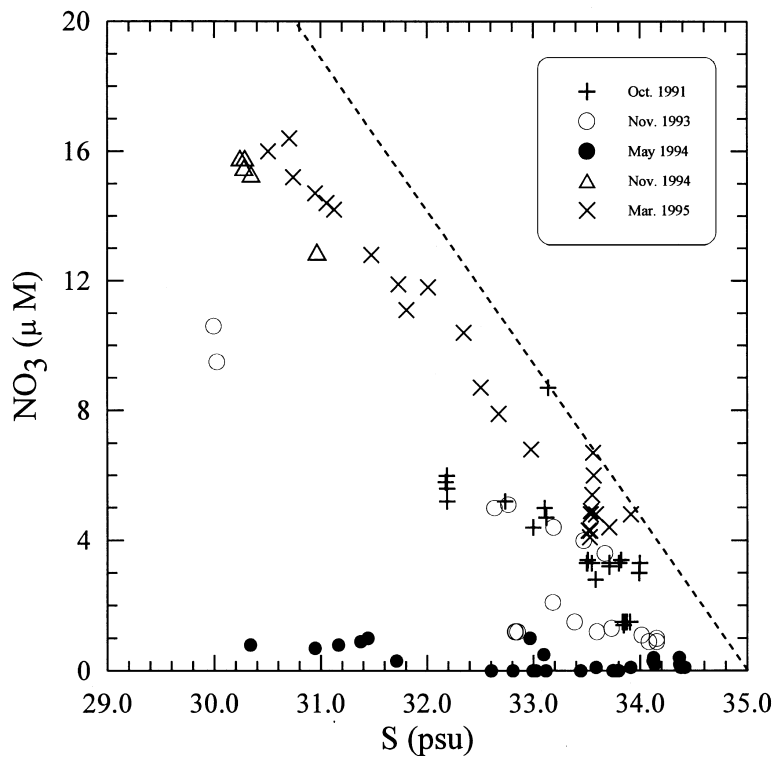

Fig. 6. The relationship between salinity $(S)$ and nitrate concentration $\left(\mathrm{NO}_{3}\right)$ in the inner shelf waters observed on various cruises. The dashed line is the hypothetical mixing line for two end members: a nitrate-devoid one with salinity at 35 psu and a nitrate-laden brackish water. (See text for detailed explanation.) 
a linear mixing line also occurred during the same cruise. Inverse trends were also shown by nitrate and Chl $a$ (Table 2), which implied nitrate loading in the CCW was also affected by nitrate uptake by phytoplankton besides mixing.

Conservative mixing for nitrate has been demonstrated for estuarine waters on the ECS coast (Edmond et al., 1985; Zhang, 1996). A hypothetical conservative mixing line is assumed for the CCW with two end members: a nutrient-devoid offshore water with salinity of 35 psu and a nutrient-laden brackish water. The slope of the mixing line is so chosen that it appears as an upper bound for nitrate concentration at any given salinity (Fig. 6). The slope of the line $(-4.7 \mu \mathrm{M} / \mathrm{psu})$ is similar to that $(-4.6 \mu \mathrm{M} / \mathrm{psu})$ observed in the Changjiang estuary (Zhang, 1996). Deviation of any data point in the $y$-direction from the mixing line gives the nitrate deficit, which presumably has been caused by phytoplankton uptake.

As expected, positive trends existed between nitrate deficit and Chl $a$ concentration for most samples from the inner shelf (Fig. 7), suggesting an increase in phytoplankton biomass associated with nitrate uptake. High correlation was found on Cruises 297 (October 1991), 373 (November 1993) and 386 (May 1994). On Cruises 405C (November 1994) and 414 (March 1995), most data points fell between two positive trend lines (Fig. 7(d)), but four data points from Cruise 414 lied considerably above the upper trend line. The two trend lines have slopes of 0.027 and $0.137 \mathrm{mg} \mathrm{Chl}(\mathrm{mmol} \mathrm{N})^{-1}$, respectively, which are similar to those observed on other cruises. The anomalously high Chl $a$ concentrations belonged to surface waters at Station 3a, which had exceptionally high temperature $\left(0.3^{\circ} \mathrm{C}\right.$ above the normal trend). The elevated temperature probably stabilized the water column and induced a spurt of rapid phytoplankton growth.

The slope of the trend lines for Chl $a$ vs. nitrate deficit varied between 0.03 and $0.14 \mathrm{mgChl}(\mathrm{mmol} \mathrm{N})^{-1}$. By comparison, the $\mathrm{Chl} a$ to nitrogen ratio in phytoplankton is usually in the range of $1-3 \mathrm{mgChl}(\mathrm{mmol} \mathrm{N})^{-1}$ (Geider, 1987), which makes it clear that the increase in phytoplankton biomass could not have accounted for the loss in nitrate. The missing nitrogen, to a larger extent, must have been removed from the water column by grazing and sinking of coagulated phytodetritus and, to a less extent, converted into dissolved organic nitrogen. Moreover, the largest nitrate deficit (up to $21 \mu \mathrm{M}$ ) was observed in May 1994, when the Chl $a$ concentrations also reached the highest level (up to $3.2 \mathrm{mg} \mathrm{m}^{-3}$ ), but the smallest nitrate deficit in March 1995 did not correspond to the lowest Chl $a$ level $\left(0.2-1.1 \mathrm{mg} \mathrm{m}^{-3}\right)$. Instead, the lowest Chl $a$ level (mostly less than $0.6 \mathrm{mg} \mathrm{m}^{-3}$ ) was found in autumn (October and November), suggesting a faster removal presumably by grazing in autumn than in spring.

A high-nitrate low-chlorophyll condition was found on the November 1993 cruise. $\mathrm{NO}_{3}$ concentration was about $9.5 \mu \mathrm{M}$ throughout the water column at Station 11 of the KEEP-Key transect (Fig. 4(b)), but Chl $a$ concentration was only $0.13 \mathrm{mg} \mathrm{m}^{-3}$ on the average (Fig. 4(c)). The highest $\mathrm{NO}_{3}$ concentration ever observed in the upwelling area indicated Kuroshio upwelling at its maximum strength. It was accompanied by the very low temperature $\left(17.1^{\circ} \mathrm{C}\right)$ and low degree of oxygen saturation $(76 \%)$ at the surface. These evidences all indicate that the surface water was freshly upwelled from depths. 

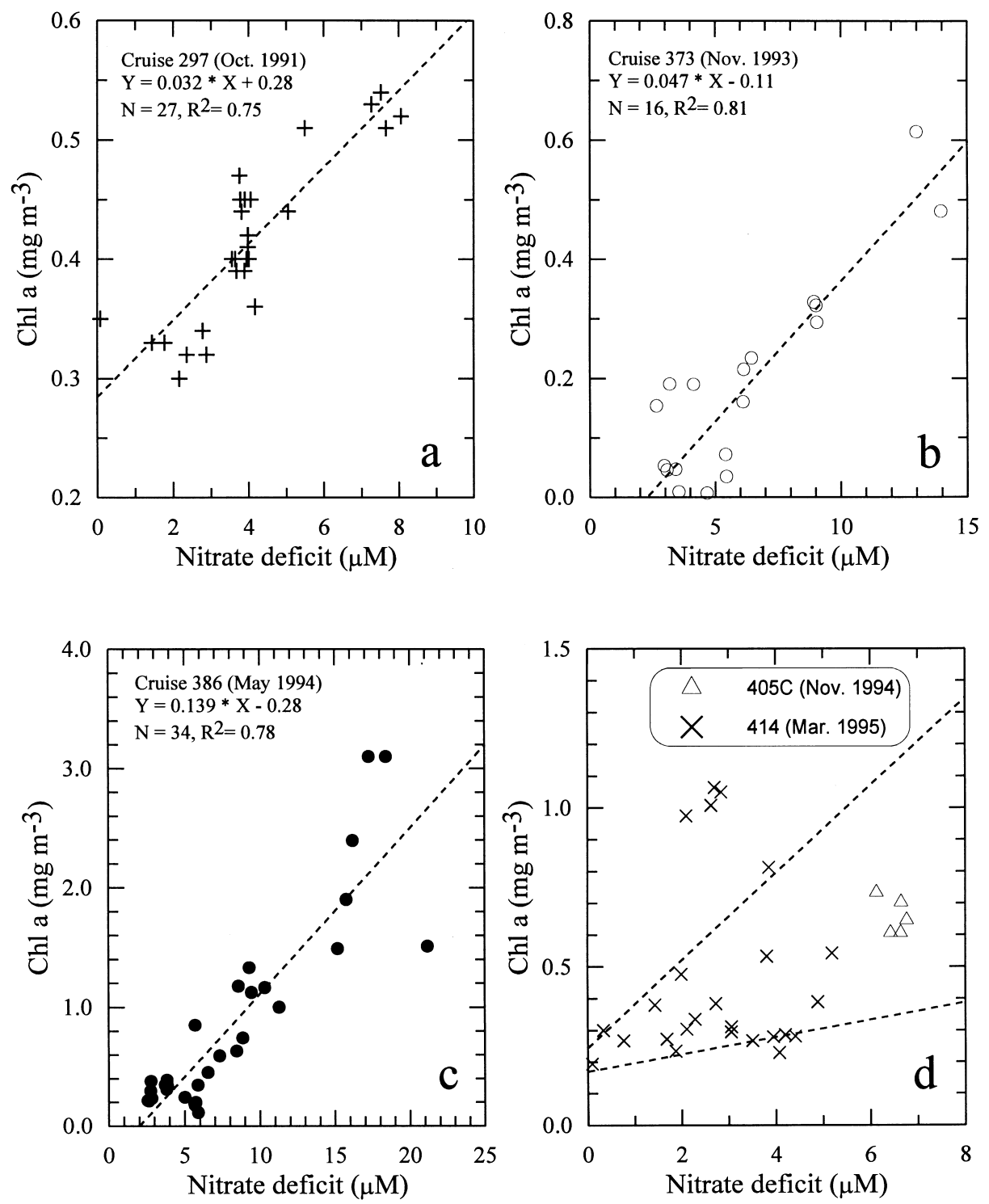

Fig. 7. The relationship between nitrate deficit and $\mathrm{Chl} a$ concentration on various cruises in the inner shelf waters onboard R/V Ocean Researcher I. (a) Cruise 297 (b) Cruise 373. (c) Cruise 386. (d) Cruises 405C and 414. The two trend lines have slopes of 0.027 and $0.137 \mathrm{mg} \mathrm{Chl}(\mathrm{mmol} \mathrm{N})^{-1}$ respectively.

Relatively low growth rate of phytoplankton in the freshly upwelled waters has been reported by Chang (1996). The high-nitrate low-chlorophyll conditions in the upwelling area must have been subject to physiological adaptation of phytoplankton. Of course, grazing might also have contributed to the low phytoplankton biomass, 
but Chang (1996) reported low grazing rate in the freshly upwelled water. Moreover, the horizontal advection associated with the upwelling divergence continuously removed phytoplankton away from the upwelling center and kept the biomass low.

Away from the upwelling center, Chl $a$ increased with decreasing nitrate, increasing temperature and saturation of dissolved oxygen in the surface water within 50-80 km from the upwelling center (Liu et al., 1995). The aging effect of the upwelled water on phytoplankton growth is apparent (Chen, 1994, 1995) and very high growth rate has been reported for the upwelling area (Shiah et al., 1996). Fig. 3(b) showed that high concentration of $\mathrm{NO}_{3}$ were occasionally observed in the middle shelves in spring and autumn. Intrusion of the Kuroshio surface layer, which usually occurs from midOctober (Tang and Yang, 1993) to mid-April (Chuang and Liang, 1994), must have pushed the upwelled water inward to the middle shelf where elevated Chl $a$ was observed (Gong et al., 1997).

\subsection{Estimation of primary production from Chl a}

\subsubsection{Relationship between Chl $a$ and primary productivity}

In the present study, a total of 22 PP data sets were obtained on seven different cruises which covered various seasons and stations in the southern ECS. Data from all four regions were pooled into analysis to delineate relationships among surface $\mathrm{Chl}$ $a$ concentration (SB), surface primary productivity (SP), IB and IP (Fig. 8). The Chl $a$ concentration and primary productivity in surface waters are well correlated with three points falling considerably above the general trend (Fig. 8(a)). The exceptionally high SP values were measured at Stations 9 and 10 on the July 1994 cruise (OR2-034) and at Station 11 on the September 1995 cruise (OR2-149), respectively. In fact, all sites from the upwelling area were higher in SP compared to other sites with the same surface Chl $a$ concentration. The values of the three exceptionally high primary productivity to $\mathrm{Chl} a$ ratios $\left(P^{\mathrm{B}}\right)$ ranged from 177 to $293 \mathrm{mgC}(\mathrm{mgChl})^{-1} \mathrm{~d}^{-1}$, suggesting that rapid phytoplankton growth was induced by upwelled nutrients and high solar radiation in July and early September, which is consistent with the previous findings of high $P_{\max }^{\mathrm{B}}$ value in the upwelling area by Shiah et al. (1996). For all data besides the three exceptions, the log-linear regression equation is

$$
\log [\mathrm{SP}]=0.985( \pm 0.079) \log [\mathrm{SB}]+4.016( \pm 0.336), \quad R^{2}=0.90 .
$$

In the plot of SB vs. IP (Fig. 8(b)), the three sites with exceptionally high SP values followed the general trend more closely, but two data points from the inner shelf fall well below the trend line, which were not included in the regression analysis. For all other data points, the regression equation is

$$
\log [\mathrm{IP}]=0.597( \pm 0.085) \log [\mathrm{SB}]+6.85( \pm 0.36), \quad R^{2}=0.77
$$

The two outliers were both obtained at Station 1 from two different cruises: the November 1994 cruise (OR1-405C) and the March 1995 cruise (OR1-414). The especially low IP observed at Station 1 reflected the very limited light penetration in the coastal zone discussed above. 

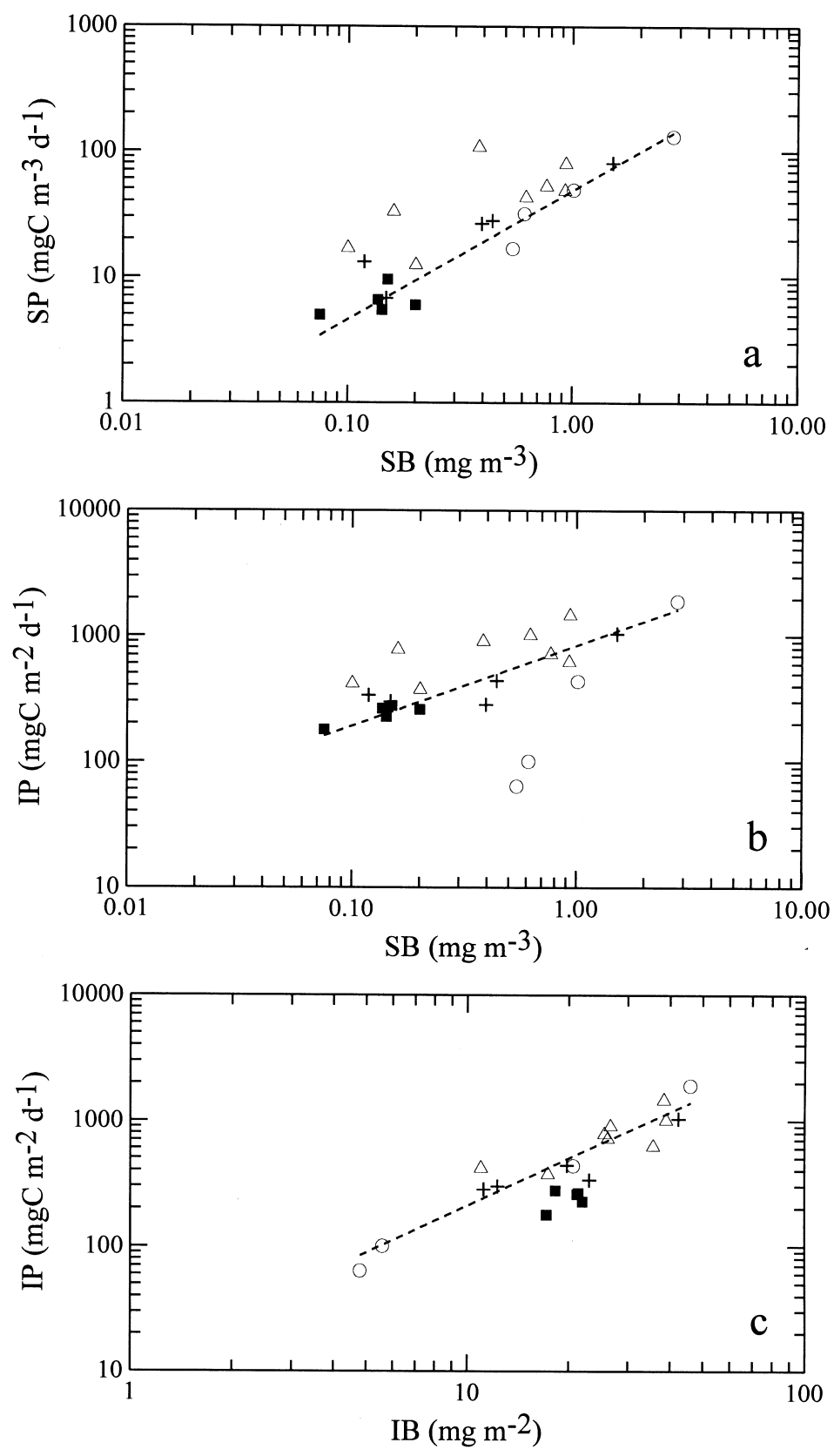

Fig. 8. The relationships between (a) surface $\mathrm{Chl} a$ concentration (SB) and primary productivity (SP), (b) surface $\mathrm{Chl} a$ concentration (SB) and euphotic zone integrated primary production (IP) and (c) euphotic zone integrated $\mathrm{Chl} a(\mathrm{IB})$ and primary production (IP) in the southern East China Sea. Inner shelf waters (O); Middle shelf waters including Station $8(+)$; Outer shelf waters $(\triangle)$; Offshore deep sea waters 
Finally, the relationship between IB and IP was examined (Fig. 8(c)). The data points representing the offshore waters (solid squares) all fall below the points for the shelf waters. The log-linear regression equation of the relationship between IB and IP for all sites except the offshore waters is

$$
\log [\mathrm{IP}]=12.1( \pm 0.11) \log [\mathrm{IB}]+2.75( \pm 0.31), \quad R^{2}=0.88
$$

The lower IP of the offshore water, compared to shelf waters with the same IB, is attributable to the very deep $\mathrm{Chl} a$ maximum where much less light is available. Fortunately, the offshore waters showed little temporal variation. Their IP to IB ratios remained fairly constant ranging between 10 and $12 \mathrm{mgC}(\mathrm{mgChl})^{-1} \mathrm{~d}^{-1}$ with a mean of $11.3 \pm 1.0 \mathrm{mgC}(\mathrm{mgChl})^{-1} \mathrm{~d}^{-1}$. Therefore, the value of IP for the deep sea waters could also be reasonably well estimated from the value of IB.

Recently, Behrenfeld and Falkowski (1997) proposed that IP can be estimated as the product of $C_{\text {surf }}$ (surface phytoplankton biomass), $P_{\mathrm{opt}}^{\mathrm{B}}$ (photoadaptive variable), $Z_{\text {eu }}$ (the depth of the euphotic zone), $F$ (irradiance-dependent function) and DL (day-length). The most sensitive terms in affecting the accuracy of this equation are $C_{\text {surf }}$ and $P_{\text {opt }}^{\mathrm{B}}$. Behrenfeld and Falkowski (1997; in their Fig. 7) argued that $P_{\text {opt }}^{\mathrm{B}}$ could be derived from a polynomial relationship with sea surface temperature (i.e. SST), although the uncertainty of the $P_{\mathrm{opt}}^{\mathrm{B}}-\mathrm{SST}$ relationship was quite high. We found that the $P_{\mathrm{opt}}^{\mathrm{B}}$-SST relationship derived from our study (Fig. 9) was quite different from the $P_{\mathrm{opt}}^{\mathrm{b}}$-SST curve proposed by Behrenfeld and Falkowski (1997), particularly for the

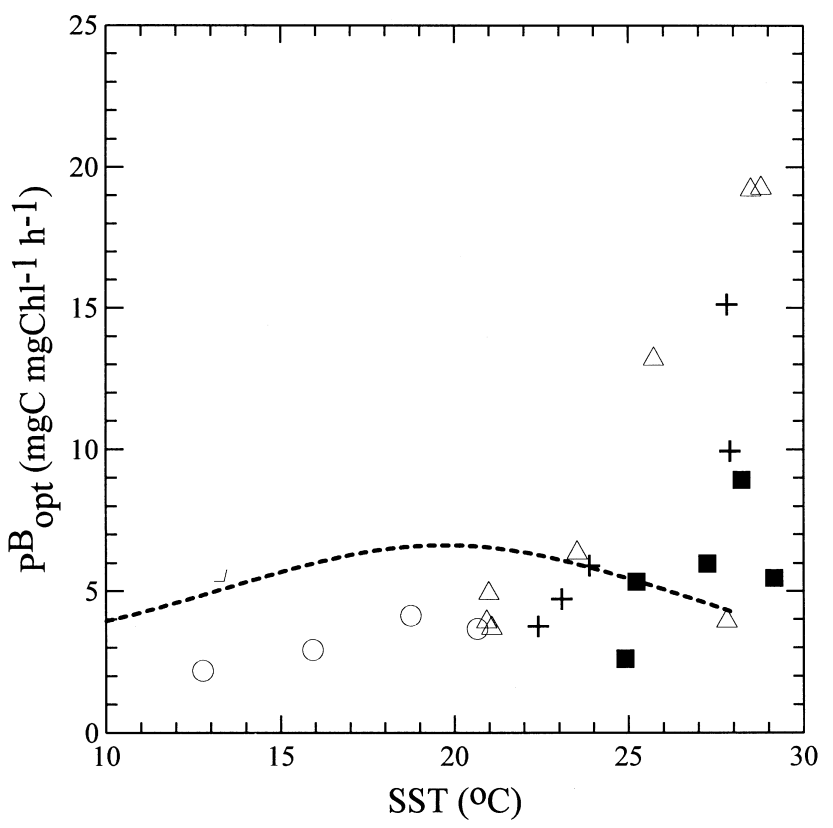

Fig. 9. The relationship between sea surface temperature (SST) and photoadaptive variable (Pbopt) in the southern East China Sea. The symbols are the same as those in Fig. 8. 
data $>25^{\circ} \mathrm{C}$. Such discrepancy and the good correlation found between IP and IB (see above) suggested that at least for the local study, our empirical approach of using of IB to estimate IP might be more appropriate than the model equation proposed by Behrenfeld and Falkowski (1997).

The relationships between SB and IP and between IB and IP can both be used to convert $\mathrm{Chl} a$ abundance into primary productivity. Of course, the latter would give more precise estimates than the former, and also more applicable to coastal zones. However, if only surface $\mathrm{Chl} a$ concentration is available, such as measurement by underway fluorometry of surface water or by satellite remote sensing, the former relationship can also provide a reasonable estimate of primary production. For a turbid environment, such as the coastal zone, correction for the limitation of light penetration is possible, if turbidity can be determined concurrently with the Chl $a$ measurement. For the underway monitoring system, a transmissometer in the pumping-through system may provide the necessary data. For satellite remote sensing system, such as the SeaWiFS, turbidity can be determined by using the $490 \mathrm{~nm}$ waveband (Austin and Petzold, 1981).

On the other hand, if the euphotic zone integrated Chl $a$ can be measured by hydrocasts or by a scanning device, such as the Scan-Fish or Aqua-Shuttle, or can be accurately estimated from surface $\mathrm{Chl} a$ concentration by modeling (e.g., Platt et al., 1988), the IP should be estimated from the IB-IP relationship. For this study, Equation (1c) was used for the calculation of IP from all Chl $a$ data obtained on KEEP cruises conducted from 1989 to 1995 (Table 1). Depths of the euphotic zone $\left(Z_{\mathrm{e}}\right)$ were either measured with a Secchi disc or PAR sensor, or calculated as $\left(4.605 / K_{\mathrm{d}}\right)$, where $K_{\mathrm{d}}$ is the total downwelling attenuation coefficient. $K_{\mathrm{d}}$ is in turn calculated from the Chl $a$ profiles using Eq. (2), which was derived from observations in the southern ECS by Gong and Liu (1995):

$$
K_{\mathrm{d}}=0.129[\mathrm{AB}]^{0.43}, \quad R^{2}=0.67,
$$

where $\mathrm{AB}$ is the averaged $\mathrm{Chl} a$ concentration in the euphotic zone.

During the calculation, iteration method was employed to find $Z_{\mathrm{e}}$ that satisfy the above relationships. For the slope sea waters, the observed average euphotic zone depth of $100 \mathrm{~m}$ was assumed for the calculation (Gong et al., 1999).

\subsubsection{Change of PP during monsoonal transitions}

In order to understand responses of sea conditions off northeastern Taiwan during transitions of the prevailing monsoon, closely scheduled cruises were conducted during the KEEP intensive observation periods. Two cruises conducted on board the R/V Ocean Researcher I during 13 September - 2 October 1992 and another two during 14 April - 5 May 1993 produced areal coverage of Chl $a$ distributions (Gong et al., 1997), which were transformed into IP maps (Fig. 10). In general, the highest values of IP occurred around the upwelling region at the shelf break northeast of Taiwan, except on the April 1993 cruise (Fig. 10(c)). The highest values of IP estimated on various cruises were $900-1500 \mathrm{mgC} \mathrm{m}^{-2} \mathrm{~d}^{-1}$. The lowest values of IP estimated were observed in the offshore water with values lower than $300 \mathrm{mgC} \mathrm{m}^{-2} \mathrm{~d}^{-1}$. 

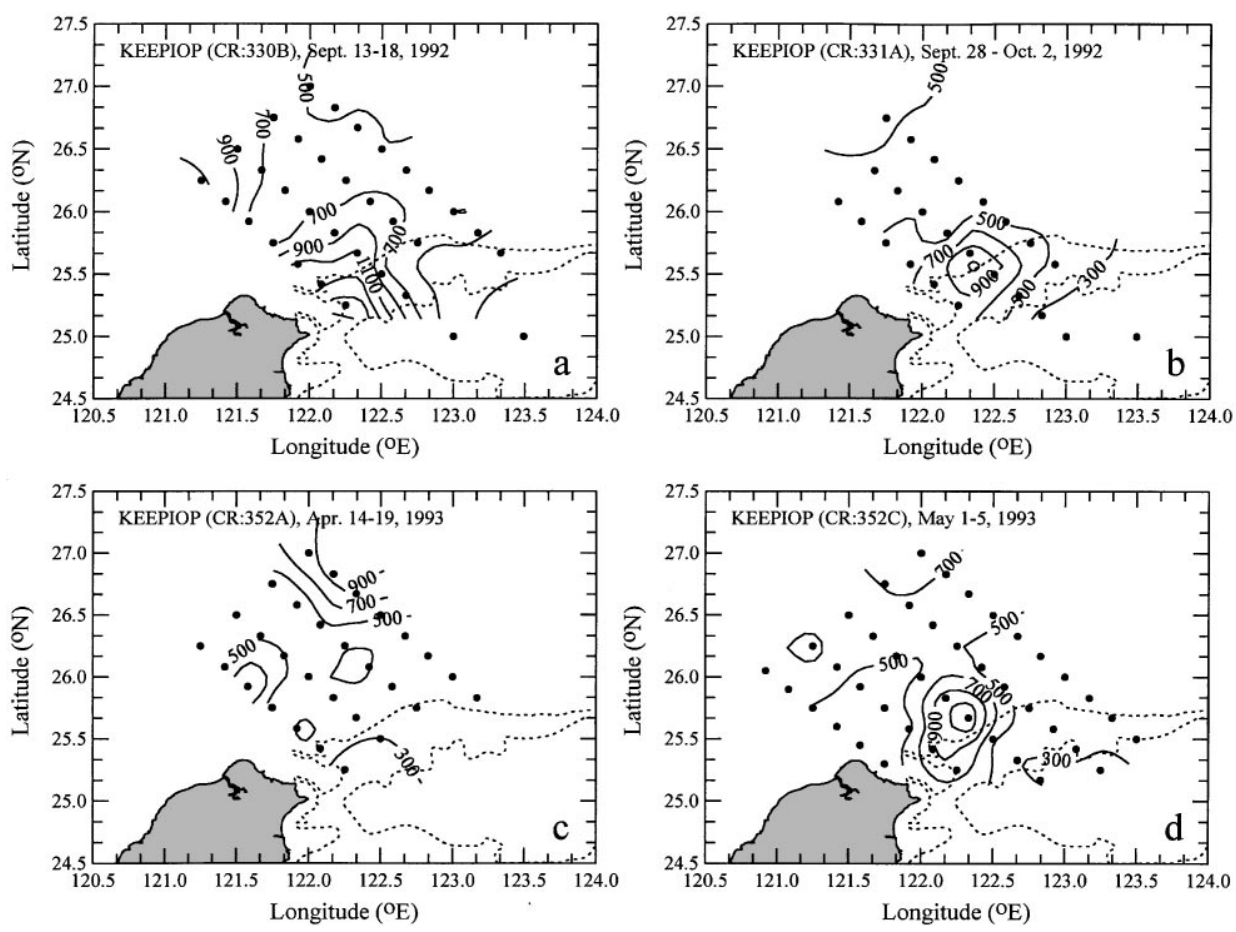

Fig. 10. The spatial distribution of the euphotic zone integrated primary production (IP) in the sea off northeastern Taiwan calculated from $\mathrm{Chl} a$ data obtained on four cruises during intensive observation periods (KEEP-IOP). The dashed curves are the isobath of $200 \mathrm{~m}$ and $500 \mathrm{~m}$.

During the onset of the northeast monsoon in mid September 1992, a very intense primary productivity (up to $1500 \mathrm{mgC} \mathrm{m}^{-2} \mathrm{~d}^{-1}$ ), which was the highest among all data (Fig. 10(a)), was observed over the upper slope just off northeastern coast of Taiwan. The high primary productivity might have been a response to the short-term intensification of upwelling at the onset of the northeast monsoon as reported by Liu et al. (1992b). Two weeks later, the high productivity center moved northeastward over the shelf edge and the PP intensity was subdued, which probably indicated a transition leading to the shelfward intrusion of the Kuroshio main stream after prolonged forcing of the northeasterly (Chao, 1991; Tang and Yang, 1993). Such intrusion appeared to suppress the upwelling moderately (Liu et al., this volume). The average IP for the area with bottom depth shallower than $1000 \mathrm{~m}$ changed from 750 to $550 \mathrm{mgC} \mathrm{m}^{-2} \mathrm{~d}^{-1}$.

The very low values of IP in the outer shelf observed on the April 1993 cruise (Fig. 10(c)) was because the region was occupied by the intruding Kuroshio surface water, which is usually depleted in nutrients (Gong et al., 1997). The upwelling was still active except that the upwelled water was pushed inward on the shelf. Rather high productivity was found in the middle shelf owing to the repletion of nutrients from the upwelled water. Two weeks later, the Kuroshio retreated from the shelf and the 
upwelling center was reestablished at the shelf edge with a well developed patch of intense primary productivity. The average IP also rebounded from 450 to $540 \mathrm{mgC} \mathrm{m}^{-2} \mathrm{~d}^{-1}$.

\subsubsection{Seasonal variation of $P P$}

Eleven monthly cruises from August 1989 to July 1990 were conducted along two KEEP-Box transects (Fig. 1) from the middle shelf to the offshore region in the southern ECS (Fig. 1). Thirteen cruises (Table 1) were conducted onboard R/V Ocean Researcher I and II from October 1991 to September 1995 along the cross-shelf KEEP-Key transect. These data provided good coverage for seasonal variation of primary productivity. The seasonal average IP values for all stations along these transects are shown in Fig. 11. In general, IP seemed to decrease slightly from the inner shelf to the middle shelf and increased again in the outer shelf and decreased abruptly further offshore (Fig. 11(c)). Seasonally, the lowest values always appeared in summer, whereas highest values occurred more often in spring or autumn. A closer examination revealed more variability. The inner shelf had very low values in autumn after intensification of the northeasterly, apparently due to increasing turbidity from sediment resuspension (Hung et al., this volume) that limited light penetration. The middle shelf enjoyed high productivity in spring and autumn, when upwelled nutrients were probably pushed shelfward by the intruding Kuroshio.

The mean IP values with standard deviations for the four regions across the shelf in the southern ECS in four seasons are listed in Table 3. The mean seasonal IP values
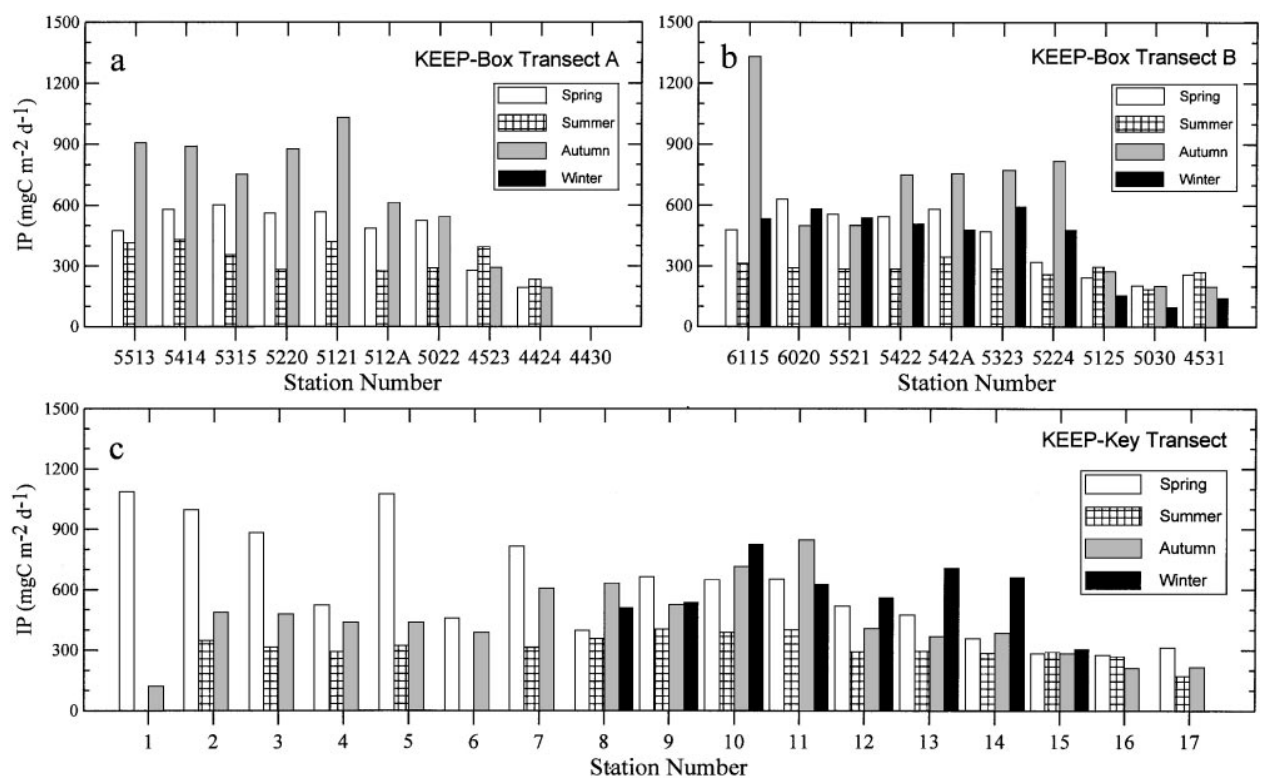

Fig. 11. The seasonal averages of the euphotic zone integrated primary production (IP) calculated from measured PP or estimated from Chl $a$ data obtained at stations on the KEEP-Box and KEEP-Key transects. 
Table 3

The mean values of euphotic zone integrated primary production $\left(\mathrm{mgC} \mathrm{m}^{-2} \mathrm{~d}^{-1}\right)$ with standard deviations for the four regions in the southern East China Sea in four seasons. Numbers in brackets are the numbers of observations

\begin{tabular}{lllllll}
\hline $\begin{array}{l}\text { Region }^{\mathrm{a}} \\
\text { Offshore }\end{array}$ & & $\begin{array}{l}\text { Spring } \\
309 \pm 38(18)\end{array}$ & $\begin{array}{l}\text { Summer } \\
276 \pm 30(10)\end{array}$ & $\begin{array}{l}\text { Autumn } \\
287 \pm 36(10)\end{array}$ & $\begin{array}{l}\text { Winter } \\
296 \pm 6(4)\end{array}$ & $\begin{array}{l}\text { Annual Mean } \\
292 \pm 15\end{array}$ \\
\hline \multirow{4}{*}{ Shelf } & Inner & $977 \pm 563(8)$ & $330 \pm 16(2)$ & $363 \pm 172(3)$ & $363^{\mathrm{b}}$ & $513 \pm 332$ \\
& Middle & $631 \pm 214(10)$ & $341 \pm 25(4)$ & $778 \pm 478(16)$ & $507(1)$ & $564 \pm 175$ \\
& Outer & $611 \pm 98(24)$ & $358 \pm 49(14)$ & $733 \pm 219(27)$ & $601 \pm 134(11)$ & $576 \pm 70$ \\
& Seasonal & $740 \pm 203$ & $343 \pm 19$ & $625 \pm 184$ & $490 \pm 134$ & $549 \pm 84$ \\
& Mean & & & & & \\
\hline
\end{tabular}

${ }^{\mathrm{a}}$ The four regions are represented by stations on the KEEP-Key (KK) transect and the KEEP-Box (KB) transects (see Fig. 1) as follows: Inner shelf (Sta. 1-3 of KK), middle shelf: (Sta. 5-7 of KK and Sta. 5513 and 6115 of KB), outer shelf (Sta. 9-11 of KK and Sta. 5315, 5220, 5121, 5323, 5422 and 542A of KB), and offshore region (Sta. 15-17 of KK and Sta 4523, 4424, 5125, 5030 and 4531 of KB).

${ }^{b}$ No observation was done for inner shelf in winter, for which the value of autumn is assumed.

for all shelf waters and the mean annual IP values for the four regions are also listed. The offshore water showed the least seasonal variability in primary productivity with a mean annual productivity of $292 \pm 15 \mathrm{mgC} \mathrm{m}^{-2} \mathrm{~d}^{-1}$, which is quite close to the recent estimate $\left(285 \mathrm{mgC} \mathrm{m}^{-2} \mathrm{~d}^{-1}\right)$ based on a photosynthesis-irradiance model (Gong et al., 1999).

For the shelf waters, the highest mean IP occurred in spring, suggesting a mild spring bloom of phytoplankton, especially in the inner and middle shelf where very high IP values above $1000 \mathrm{mgC} \mathrm{m}^{-2} \mathrm{~d}^{-1}$ were found (Fig. 11(c)). The very high standard deviations for the inner and middle shelves in spring (Table 3) also reflected the drastic change of primary productivity prior and during the spring bloom. The IP values of the shelf waters were lowered considerably in summer approaching that of the offshore water. In autumn, the inner shelf water remained in low productivity, whereas the middle and outer shelf witnessed a strong comeback, reflecting intensification of the upwelling during the transition of the prevailing wind. The mean IP for winter was slightly lower than that for spring, but the winter value was more uncertain because of scarcity of data for the inner and middle shelf.

The mean annual IP values of the three regions on the shelf were surprisingly close, ranging from 513 to $576 \mathrm{mgC} \mathrm{m}^{-2} \mathrm{~d}^{-1}$ (Table 3). The highest value belongs to the outer shelf, where upwelling enhanced the phytoplankton growth. Note that the value for the inner shelf is less reliable due to lack of observations in winter, for which the value for autumn was assumed for the calculation of the annual mean. The overall annual mean for all shelf waters was $549 \pm 84 \mathrm{mgC} \mathrm{m}^{-2} \mathrm{~d}^{-1}$, which is about twice the value for the offshore water. The mean annual primary production per unit area on shelves bordering western boundary currents varies in a wide range, from 80 to $960 \mathrm{mgC} \mathrm{m}^{-2} \mathrm{~d}^{-1}$, with a mean of $380 \mathrm{mgC} \mathrm{m}^{-2} \mathrm{~d}^{-1}$ (Walsh, 1988). The mean value $\left(549 \pm 84 \mathrm{mgC} \mathrm{m}^{-2} \mathrm{~d}^{-1}\right)$ that we obtained for the southern ECS is above average 
among similar environments, but close to the median value. Compared to the South Atlantic Bight (SAB), where the annual mean is $390 \mathrm{mgC} \mathrm{m}^{-2} \mathrm{~d}^{-1}$ (Menzel et al., 1993), our study area is more productive. Broken down into the inner, middle and outer shelves, the mean values are 620,248 and $360 \mathrm{mgC} \mathrm{m}^{-2} \mathrm{~d}^{-1}$, respectively, for the SAB. For our study area, the middle and outer shelves were both considerably more productive, while the inner shelf was slightly less productive (Table 2). In fact, very high productivity, with an average of $2000 \mathrm{mgC} \mathrm{m}^{-2} \mathrm{~d}^{-1}$, also occurs in the $\mathrm{SAB}$ during upwelling events, but under non-upwelling conditions the primary production is less than $200 \mathrm{mgC} \mathrm{m}^{-2} \mathrm{~d}^{-1}$ (Yoder et al., 1985). The higher productivity at the middle and outer shelves of our study is apparently attributable to the more persistently Kuroshio upwelling, which provides a greater nutrient supply to the shelf than the upwelling events in the SAB (Liu et al., this issue).

\section{Summary and conclusion}

The spatial and temporal variation of Chl $a$ and primary productivity in the southern East China Sea was closely related with the chemical hydrographic conditions as observed in the KEEP program from 1989 to 1995 . The lowest surface Chl $a$ concentrations were found in the offshore water, where the surface mixed layer remained oligotrophic throughout the year due to strong stratification. However, the euphotic zone integrated Chl $a$ abundance in the offshore water was usually higher than those in some shelf regions owing to a notable subsurface Chl $a$ maximum around the depth of $70 \mathrm{~m}$. Stratification of water column also occurred on the shelf in summer due to high sea surface temperature and spread-out of a low salinity water, which originated probably mainly from the South China Sea and was fed through the Taiwan Strait. As a result of stratification, the surface layer was depleted in nutrients and a subsurface Chl $a$ maximum was developed at the depths of $30-50 \mathrm{~m}$ across the shelf in summer.

In other seasons, the shelf waters were usually enriched in nutrients throughout the water column due to more vigorous vertical mixing as well as a rich supply of nutrients from river runoff for the inner shelf and from the Kuroshio upwelling for the outer shelf. High-nutrient low-chlorophyll conditions often occurred in the upwelling center and the inner shelf. In the former area, phytoplankton grew gradually in the freshly upwelled water, which was low in Chl $a$ to begin with. In the latter area, high turbidity caused by wind-induced sediment resuspension limited light penetration, and, thus, limited phytoplankton growth. Nitrate removal in the inner shelf water was usually accompanied by increase in Chl $a$ concentration, but the resultant phytoplankton biomass may have likely been controlled by grazing and other removal processes, which were higher in autumn than in spring.

Despite complicated controlling factors for Chl $a$ distribution in the shelf environment, the euphotic zone integrated Chl $a$ abundance was well correlated with the euphotic zone integrated primary production. This relationship was used to estimate the primary production in the shelf waters from observed vertical profiles of Chl $a$, which had a better spatial and temporal coverage than the measurements of primary 
productivity. However, the offshore water showed a consistent negative deviation from the above relationship, implying it was less productive, for the same amount of $\mathrm{Chl} a$, than the shelf water due to its rather deep Chl $a$ maximum. Fortunately, the seasonal variability of the offshore water was the lowest. A constant primary productivity to $\mathrm{Chl} a$ ratio of $11.3 \pm 1.1 \mathrm{mgC}(\mathrm{mgChl})^{-1} \mathrm{~d}^{-1}$ was used for the conversion. A reasonably good correlation was also found between the euphotic zone integrated primary production (IP) and the surface $\mathrm{Chl} a$ concentration for shelf waters and the offshore waters except the inner shelf water with high turbidity. Such relationship provides a means for estimation of IP from satellite remotely sensed data of sea surface Chl $a$.

The average primary productivity in the shelf waters was the lowest in summer. The mean IP was $343 \pm 19 \mathrm{mgC} \mathrm{m}^{-2} \mathrm{~d}^{-1}$ for the shelf water with little variation across the shelf. In other seasons, there was a strong spatial variability. The outer shelf enjoyed a persistent supply of upwelled nutrients, which sustained a stable IP ranging from 601 to $733 \mathrm{mgC} \mathrm{m}^{-2} \mathrm{~d}^{-1}$. The inner shelves showed the highest IP in spring, suggesting a mild spring bloom. After summer, the IP in the middle and outer shelf bounced back to about $733-778 \mathrm{mgC} \mathrm{m}^{-2} \mathrm{~d}^{-1}$, but that in the inner shelf remained low ( $363 \mathrm{mgC} \mathrm{m}^{-2} \mathrm{~d}^{-1}$ ) probably owing to light-limitation in the turbid water column. In spite of the spatial variability in various seasons, the annual mean IP values across the shelf were surprisingly uniform, $513-576 \mathrm{mgCm}^{-2} \mathrm{~d}^{-1}$ with an overall mean IP of $549 \pm 84 \mathrm{mgC} \mathrm{m}^{-2} \mathrm{~d}^{-1}$ for the whole shelf in the southern ECS. The IP in the offshore water showed a slight seasonal variation, ranging between 276 and $309 \mathrm{mgC} \mathrm{m}^{-2} \mathrm{~d}^{-1}$ with a mean annual IP of $292 \pm 15 \mathrm{mgC} \mathrm{m}^{-2} \mathrm{~d}^{-1}$.

\section{Acknowledgements}

The authors wish to thank Mr. B.-W. Wang and K.-J. Liu for assistance with nutrient and chlorophyll analyses. We are also grateful to the captain and crews of the $\mathrm{R} / \mathrm{V}$ Ocean Research I and II for technical assistance on board. This research was supported by the National Science Council grants of NSC 85-2611-M-019-014 K2, NSC86-2611-M-019-008 K2 (to GCG) and NSC88-2611-M-002-001 (to KKL). This is National Center for Ocean Researche (NCOR) Contribution Number 13. The suggestions and comments from Dr. R. Sombrotto and Dr. L. Tupas are very appreciated.

\section{References}

Austin, R.W., Petzold, T.J., 1981. The determination of the diffuse attenuation coefficient of sea water using the coastal zone color scanner. In: Gower, J.F.R. (Ed.), Oceangraphy from Space. Plenum Press, New york, pp. 239-256.

Beardsley, R.C., Limeburner, R., Yu, H., Cannon, G.A., 1985. Discharge of the Changiiang (Yangtze River) into the East China Sea. Continental Shelf Research 4, 57-76.

Behrenfeld, M.J., Falkowski, P.G., 1997. Photosynthetic rates derived from satellite-based chlorophyll concentration. Limnology and Oceanography 42, 1-20. 
Chang, J., 1996. The estimation of phytoplankton growth rate and its roles in the carbon cycle in the southern East China Sea using the dilution culture method (2). In: Proceeding of 1996 Workshop for Oceanographic Research Programs. Taichung, Taiwan, pp. 140-144.

Chao, S.-Y., 1991. Circulation of the East China Sea, a numerical study. Journal of Oceanographic Society of Japan 46, 273-295.

Chen, Y.-L.L., 1994. The importance of temperature and nitrate to the distribution of phytoplankton in the Kuroshio-induced upwelling northeast of Taiwan. Proceedings of the National Science Council (ROC), Part B 18, 44-51.

Chen, Y.-L.L., 1995. Phytoplankton composition and productivity in response to the upwelling off northeastern Taiwan. Proceedings of the National Science Council (ROC), Part B 19, 66-72.

Chen, A.C.T., 1996. The Kuroshio intermediate water is the major source of nutrients on the East China Sea continental shelf. Oceanologica Acta 5, 523-527.

Chern, C.-S., Wang, J., Wang, D.-P., 1990. The exchange of Kuroshio and East China Sea shelf water. Journal of Geophysical Research 95, 16017-16023.

Chuang, W.-S., 1986. A note on the driving mechanism of current in the Taiwan Strait. Journal of Oceanographic Society Japan 43, 355-361.

Chuang, W.-S., Liang, W.-D., 1994. Seasonal variability of intrusion of the Kuroshio water across the continental shelf northeast of Taiwan. Journal of Oceanography 50, 531-542.

Duce, R.A., Tindale, N.W., 1991. Atmospheric transport of iron and its deposition in the ocean. Limnology and Oceanography 36, 1715-1726.

Edmond, J.M., Spivack, A., Grant, B.C., Hu, M.-H., Chen, Z., Chen, S., Zeng, X., 1985. Chemical dynamics of the Changjiang estuary. Continental Shelf Research 4, 17-36.

Eppley, R.W., Stewart, E., Abbott, M.R., Heyman, U., 1985. Estimating ocean primary production from satellite chlorophyll. Introduction to regional differences and statistics for the southern California Bight. Journal of Plankton Research 7, 57-70.

Geider, R.J., 1987. Light and temperature dependence of the carbon to chlorophyll $a$ ratio in microalgae and cyanobacteria: implications for physiology and growth of phytoplankton. New Phytology 106, $1-34$.

Gong, G.-C. (1992) Chemical hydrography of the Kuroshio front in the sea northeast of Taiwan. Ph.D. Thesis, Institute of Oceanography, National Taiwan University.

Gong, G.-C., Chang, J., Wen, Y.-H., 1999. Estimation of annual primary production in the Kuroshio waters northeast of Taiwan using a photosynthesis-irradiance model. Deep-Sea Research 46, 93-108.

Gong, G.-C., Chen, Y.L., Liu, K.-K., 1996. Chemical hydrography and Chl $a$ distribution in the East China Sea in summer: implications in nutrient dynamics. Continental Shelf Research 16, 1561-1590.

Gong, G.-C., Liu, K.-K. (1995). The relationship between mean chlorophyll $a$ concentration within one optical depth and euphotic zone integrated biogenic matters. In: Proceedings of Space Remote Sensing of Subtropical Oceans (SRSSO), Taipei, Taiwan, pp. 15A3-7-15A3-10.

Gong, G.-C., Liu, K.-K., Pai, S.-C., 1995a. Prediction of nitrate concentration from two end member mixing in the southern East China Sea. Continental Shelf Research 15, 827-842.

Gong, G.-C., Shiah, F.-K., Liu, K.-K., Chuang, W.-S., Chang, J., 1997. Effect of the Kuroshio intrusion on the chlorophyll distribution in the southern East China Sea north of Taiwan during spring, 1993. Continental Shelf Research 17, 79-94.

Gong, G.-C., Shyu, C.-Z., Shin, W.-H., Liu, K.-K., 1992. Temperature fluctuation of the cold water off northern Taiwan: June-December, 1990. Acta Oceanographica Taiwanica 28, 118-127.

Gong, G.-C., Yang, W.-R., Chang, J., 1995b. In vivo fluorescence-derived Chl $a$ concentration in the southern East China Sea. Acta Oceanographica Taiwanica 34, 73-85.

Gong, G.-C., Yang, W.-R., Wen, Y.-H., 1993. Correlation of chlorophyll $a$ concentration and Sea Tech fluorometer fluorescence in seawater. Acta Oceanographica Taiwanica 31, 117-125.

Hayward, T.L., Venrick, E.L., 1982. Relation between surface chlorophyll, integrated chlorophyll and integrated primary production. Marine Biology 69, 247-252.

Huang, K.-M., Lin, S., 1995. The carbon-sulfide-iron relationship and sulfate reduction rate in the East China Sea continental shelf sediments. Geochemical Journal 29, 301-315. 
Liu, K.-K., Gong, G.-C., Lin, S., Shyu, C.-Z., Yang, C.-Y., Wei, C.-L., Pai, S.-C., Wu, C.-K., 1992a. The year-round upwelling at the shelf break near the northern tip of Taiwan as evidenced by chemical hydrography. Terrestrial, Atmospheric and Oceanic Sciences 3, 234-276.

Liu, K.-K., Gong, G.-C., Lin, S., Shyu, C.-Z., Pai, S.-C., Wei, C.-L., Chao, S.-Y., 1992b. Response of Kuroshio upwelling to the onset of northeast monsoon in the sea north of Taiwan: observations and a numerical simulation. Journal of Geophysical Research 97, 12 511-12 526.

Liu, K.-K., Pai, S.-C., Yang, C.-Y., Wei, C.-L., Gong, G.-C., 1993. Nitrate distribution in the sea north of Taiwan during period of northeastern monsoon. In: Su, J., Chuang, W.-S., Hsueh, Y. (Eds.), Proceedings Conference on Physical and Chemical Oceanography of the China Seas. China Ocean Press, Beijing, pp. $510-521$.

Liu, K.-K., Lai, Z.-L., Gong, G.-C., Shiah, F.-K., 1995. Distribution of particulate organic matter in the southern East China Sea: implications in production and transport. Terrestrial, Atmospheric and Oceanic Sciences 6, 27-45.

Longhurst, A.R., Harrison, W.G., 1989. The biological pump: profiles of plankton production and consumption in the upper ocean. Progress in Oceanography 22, 47-123.

Lorenzen, C.J., 1970. Surface chlorophyll as an index of the depth, chlorophyll content and primary productivity of the euphotic layer. Limnology and Oceanography 15, 479-480.

Mantyla, A.W., Venrick, E., Hayward, T., 1995. Primary production and chlorophyll relationships, derived from ten years of CALCOFI measurements. CALCOFI Report 36, 159-166.

Martin, J.H., 1991. Iron as a limiting factor. In: Falkowski, P. (Ed.), Primary Productivity and Biogeochemical Cycles in the Sea. Plenum Press, New York, pp. 123-137.

Menzel, D.W., Pomeroy, L.R., Lee, T.N., Blanton, J.O., Alexander, C.R., 1993. Chapter 1 Introduction. In: Menzel, D.W. (Ed.), Ocean Processes: U.S. Southeast Continental Shelf. U.S. Department of Energy, Office of Scientific and Technological Information, Oak Ridge, TN, pp. 1-8.

Morel, A., 1991. Light and marine photosynthesis: a spectral model with geochemical and climatological implications. Progress in Oceanography 26, 263-306.

Pai, S.-C., Gong, G.-C., Liu, K.-K., 1993. Determination of Dissolved Oxygen in Seawater by Direct Spectrophotometry of Total Iodine. Marine Chemistry 41, 343-351.

Parsons, T.R., Maita, Y., Lalli, C.M., 1984. A Manual of Chemical and Biological Methods for Seawater Analysis. Pergamon Press, New York.

Platt, T., Sathyendranath, S., Caverhill, C.M., Lewis, M.R., 1988. Ocean primary production and available light: further algorithms for remote sensing. Deep Sea Research 35, 855-879.

Ryther, J.H., Yentsch, C.S., 1957. The estimation of phytoplankton production in the ocean from chlorophyll and light data. Limnology and Oceanography 2, 281-286.

Shaw, P.T., 1989. The intrusion of water masses into the southwest of Taiwan. Journal of Geophysical Research C 12, 18 213-18 226.

Shiah, F.-K., Gong, G.-C., Liu, K.-K., 1995. A preliminary survey on primary productivity measured by the ${ }^{14} \mathrm{C}$ assimilation method in the KEEP area. Acta Oceanographica Taiwanica 34, 1-15.

Shiah, F.-K., Gong, G.-C., Liu, K.-K., 1996. Light effect on phytoplankton photosynthetic performance in the southern East China Sea north of Taiwan. Botanical Bulletin of Academica Sinica 37, 133-140.

Smith, R.C., Baker, K.S., 1978. The bio-optical state of ocean waters and remote sensing. Limnology and Oceanography 23, 247-259.

Strickland, J.D.H., Parsons, T.R., 1972. A practical handbook of seawater analysis. Fisheries Research Board of Canada, Ottawa, Canada.

Tang, T.-Y., Yang, Y.-T., 1993. Low frequency current variability on the shelf break northeast of Taiwan. Journal of Oceanography 49, 193-210.

Walsh, J.J., 1988. On the Nature of Continental Shelves. Academic Press, San Diego.

Wang, J., Chern, C.-S., 1988. On the Kuroshio branch in the Taiwan strait during wintertime. Progress in Oceanography 21, 469-491.

Wong, G.T.-F., Pai, S.-C., Liu, K.-K., Liu, C.-T., Chen, C.-T.A., 1991. Variability of the chemical hydrography at the frontal region between the East China Sea and the Kuroshio northeast of Taiwan. Estuarine Coastal Shelf Science 33, 105-120. 
Yoder, J.A., Atkinson, L.P., Bishop, S.S., Blanton, J.O., Lee, T.N., Pietrafesa, L.J., 1985. Phytoplankton dynamics within Gulf Stream intrusions on the southeastern United States continental shelf during summer 1981. Continental Shelf Research 4, 611-635.

Yoder, J.A., Verity, P.G., Bishop, S.S., Hoge, F.E., 1993. Phytoplankton Chl $a$, primary production and nutrient distributions across a coastal frontal zone off Georgia, U.S.A.. Continental Shelf Research 2/3, 131-141.

Zhang, J., 1996. Nutrient elements in large Chinese estuaries. Continental Shelf Research 16, 1023-1045. 